\title{
Digital Design Thinking and Innovation - A Neurostrategic Prospective
}

\author{
Dr Arabinda Bhandari. \\ MBA, PGCBM(XLRI). Ph.D (Strategic Management). School of Management. Presidency University
}

\begin{abstract}
:
This paper investigates opportunities of digital technology for design thinking and innovation from a neurostrategic competitive advantage prospective. By using the empirical epistemological systematic analysis based on Kuhn scientific revolution models, this study suggests, by a scientific analysis in the journal from 2010 until now. The conclusion is that digital technology tools are showing sign of future success in management science but there is still much confusion and misinterpretation about what would be behavioral and neuroscientific research that can help design thinking and innovation. As a novelty, this research will propose a discussion to define a probable model for an organization to get a sustainable competitive advantage by using the digital technology in the area of design thinking and innovation with the help of neurostrategic concept.
\end{abstract}

Keywords: Design Thinking; Neurostrategy; SMAC; Behavioral Strategy; Strategic Innovation.

DOI: $10.7176 / \mathrm{EJBM} / 11-1-07$

\section{Introduction:}

Every organization operates on a theory of a business, organization vision covert this theory into action. As the external factors of the organization are continuously changing, organizations are facing tremendous completion in the volatility, uncertainty, complexity, ambiguity (VUCA) environment. Nowadays with the help of technology or through reverse engineering, the competitor can know the ingredient of the products and can sale the similar product in the marketplace at a much lower price.

Over the past couple of decade, the term design thinking has transmuted from a trendy catchword used in the start-up community, to a widely accepted concept in the wider business world. Entrepreneurs have long spoken of the need to think outside the box and find creative new ways to develop products and services. Design thinking (defining the problem, empathizing, ideating and innovating) using investigation, and facilitates results through radical cross-boundary thinking in order to effect social change by using a human-centered approach.

The concept of design thinking is based on a simple guideline of empathy to the customer, however the reason of failure of any product and service is due to that executive do not pay much attention to the need of the customer.

Technology has given us freedom to exchange our thought and idea with millions of people across the globe. With the help of internet and SMAC(SMAC, S=Social, M= Mobile, A= Analytics, C= Cloud Computing) technology, smartphone and tablet revolutionized the organization's work and now can storing of information become easy and can be accessible from anywhere and anytime.

As consumers always demand more sophisticated updated products and services, there's no doubt that technology plays a vital role in how businesses continue to evolve in their quest for innovation. But with so much knowledge available at our fingertips, does this spell the end for the old-fashioned human-centered interaction between businesses and customers? This is where design thinking plays a critical role in how an organization expresses their business models.

At the core of design thinking is the capability to empathize with the people you are designing a service or product for them. As we gradually move towards a world conquered by technology, preserving products and services which are operated by humans rather than machines has never been more important. Artificial intelligence, the Internet of Things and big data have transformed our lives exponentially, but their success still depends on understanding the root causes of the behaviors of the humans behind the technology.

Big data analysis can reveal the expenditure habits of a customer. But unable to explore why customer makes certain choice in first attempt. Failing to recognize why people behave in a certain way will gives a wrong result of a research. Big data is often decontextualized from value, culture, aspiration and motivation angle. Here comes the role of neurostrategy(Please see figure 1).

Neurostrategy is an interdisciplinary in nature which analyse the human nervous system by studying the brain when individual takes a decision (Please See figure 1). This analysis can be perform through various medical test like fMRI, EEG, TMS.

Powell et al. (2011) stated that behavioral strategy combines cognitive and social mindset with strategic management and practice by seeing the cognition, emotion and social collaboration factors of human with incorporation of strategic management process.

According to Gippel(2013), design thinking is more multifarious in nature and has a connection with psychology, anthropology, sociology and economic. Additionally, the cluster "Organizational neuroscience" 
(Ward et al, 2015), where all activity of an organization can be scan through the tool of neuroscience.

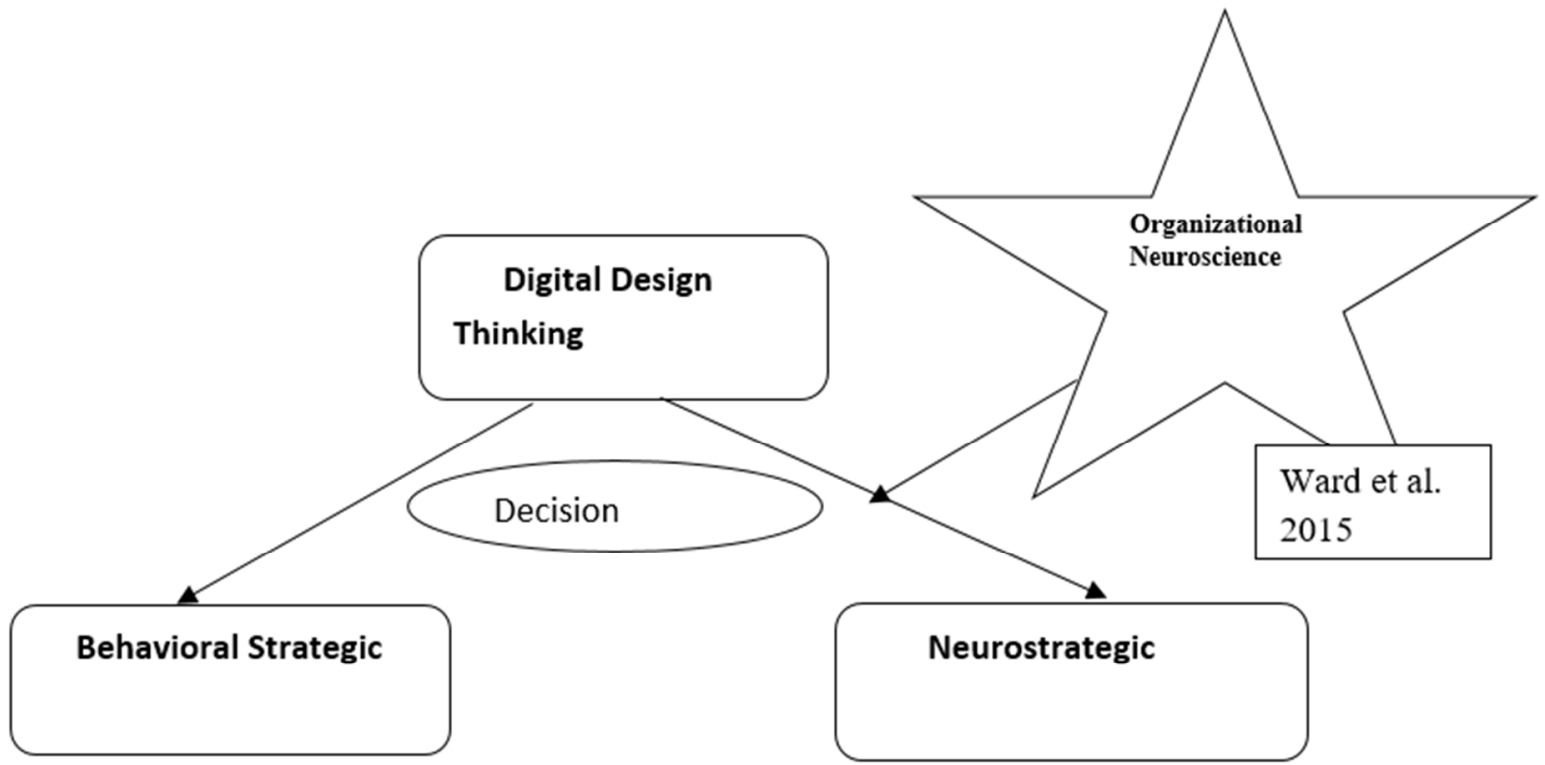

Figure: 1, Source: Author's own idea.

To become a successful, organization requisite to combine analytics with qualitative data for better understanding of customer's activities. This is the key to developing inventions that resonate with people on an emotional level.

This lack of empathy with customers can lead to the Egocentric empathy gap in decision-makers. This happens when businesses project their own feelings for products and services onto customers and steadily overestimate the similarity between what they value and what the public values. As a result, these organization often fail to generate products and services that give people value for money.

\section{Theoretical Background:}

Strategic decision making is a cognitive process. Teece at al.(1979) stated that strategic decision making process should be based on rationality. Eminent expert in this field like Eisenhardt (1989)and Klein (1999) had talked about the essential elements which can influences the rationality process. Chandler (1962) had already talked about the intuition which is part of executive's behavior that differentiate the performance of an executive while they are in strategic decision making process.

Powell(2011) believe that thoughts, social relations and feelings of an manager influence the performance of an organization. Kahneman and Tversky (1979) noted that because of construction of mental shortcut and cognitive biases of the individual, the outcome of decision making process of individual differ from executive to executive.

In $19^{\text {th }}$ century, the Homo Economicus concept by Sturt Mill stated that human seek to minimize the risk and maximize the return of any action. Da Rocha and Rocha (2011) stated that use of logic and reason play an important role in strategic decision making process. Herbert Simon(1947) in bounded rationality concept talked about that helplessness of leaders to make a decision when there is a limitation of information from environment.

Tversky \& Kahneman (1974) concluded that there are numbers of personal factors and other factors which are not external and internal in nature and not linked with decision may influence the decision making process. In addition, human takes decision based on cognitive shortcut of their experience.

Since long, we don't used to consider the emotional factors in the process of strategic decision making (Da Jong \& Veijer, 2014). ). Powell (2014) concluded that Strategic Management is 75\% personal and 25\% is impersonal. As per Thaler (2000), executive may follow quasi-rational model by doing some systematic error of judgement. In strategic Management, near rational individual's decision making process is difficult to judge by mathematical models. But it can be partly solve by the studies involving cognitive neuroscience.

Objective of the study: The objective of the study is to find out how designing thinking can power creative problem solving, help in Innovation and deliver value to an organization from a neurostrategic prospective window.

\section{Literature review:}

Designing thinking has three phases of a circle, which is including inspiration, ideation, and implementation. The designer of the product spends much more time in designing stage prototyping the solution, testing and designing feedback when they will come for a feasible solution. Designers usually engage in four types of work: 
observations, frameworks, imperatives, and solutions that can help to improve the digital design thinking.

Digital design thinking is a process used by designers to resolve multifaceted difficulties and discover the necessary solutions for clients. When to do a designing thinking, an organization should emphasis on users' know-hows, especially their emotional ones. To shape empathy with the user or customer, a designing centric organization may have to permit the employee to witness behavior and draw a decision about what customer needs and want. Below are the few findings of the author about design thinking (Please see Table 1).

\begin{tabular}{|c|c|c|}
\hline Year & Author's Name & Finding \\
\hline 1990 & Evans, McNeill, \& Beakley & This is a natural and ubiquitous activity of human. \\
\hline 1996 & Simon & It is extensively distinctive central activity of engineering. \\
\hline 1997 & Braha \& Maimon, & Engineering lacks sufficient scientific foundations. \\
\hline 1999 & Dorner & It is based on cloudy idea of a product/ service how it should work. \\
\hline 1999 & Akin \& Akin, & $\begin{array}{l}\text { Based on the flexible problem solving strategies, a good designer should } \\
\text { meets the requirement of a situation. }\end{array}$ \\
\hline 2003 & Braha and Reich & $\begin{array}{l}\text { Design procedure as a general procedure where designers modify either } \\
\text { the tentative or current design or the requirement and condition, based on } \\
\text { new evidence that has become available. }\end{array}$ \\
\hline 2005 & David Kelley & A methodology to innovate routinely \\
\hline 2005 & David Kelley & Help the organization to put the strategy into vision. \\
\hline 2006 & David Burney & An imperative business strategy for innovative problem solving. \\
\hline 2006 & Dunne \& Martin, & $\begin{array}{l}\text { Products and services design is the main constituent of any business } \\
\text { attractiveness, to the degree that many known organization have dedicated } \\
\text { themselves to suitable design thinker. }\end{array}$ \\
\hline 2007 & Owen, 2007). & $\begin{array}{l}\text { Finders or creators are the two diverse ways by which imaginative people } \\
\text { incline to work }\end{array}$ \\
\hline 2010 & Shute \& Becker & $\begin{array}{l}\text { Being prosperous in today's extremely technological and worldwide } \\
\text { competitive world needs a person to develop and use a diverse set of skill } \\
\text { that were required before }\end{array}$ \\
\hline 2010 & Hatchuel et al. & $\begin{array}{l}\text { Design activity motivated on innovation can emphasize future strategies } \\
\text { based on the conception of desirable unknowns. }\end{array}$ \\
\hline 2011 & Morin & $\begin{array}{l}\text { Marketing research should focused to know the contrast of the } \\
\text { indications in the dependent level of oxygenated blood (BOLD). To a } \\
\text { stimulus, some brain get more oxygenated blood than they had received } \\
\text { earlier. }\end{array}$ \\
\hline 2012 & Dolley & $\begin{array}{l}\text { Current neuroscience tools which help to see into human brains and so that } \\
\text { open a way to psychological policymaking process - the black box of the } \\
\text { brain }\end{array}$ \\
\hline 2013 & Al Pop et al & $\begin{array}{l}\text { Externally triggered customer buying decision emotion are better } \\
\text { understand by physiological neuronal database. }\end{array}$ \\
\hline 2015 & Agarwal \& Dutta, & $\begin{array}{l}\text { Neuromarketing research eliminates subjectivity and uncertainty by going } \\
\text { right to computing observable brain behavior. Neuroscience has played a } \\
\text { significant role in cultivating behavioral predictions and advancing the } \\
\text { acceptance of consumers }\end{array}$ \\
\hline 2015 & Ward et al & $\begin{array}{l}\text { The impact of Neuroscience are more on public and press because of its } \\
\text { scientific criteria. }\end{array}$ \\
\hline 2017 & Cristofaro & $\begin{array}{l}\text { Behavioral strategy is getting harmonizing by the help of neuroscience } \\
\text { criteria. }\end{array}$ \\
\hline 2017 & Powell & $\begin{array}{l}\text { Psychology research has shown that people do not always act sensibly as } \\
\text { per the Homo Economicus believers. }\end{array}$ \\
\hline
\end{tabular}

Table 1: Literature Review 


\section{Research Gap:}

The above-mentioned authors have talked about the designing thinking as a strategic guideline, but no one has talked talk about how neurostrategy will help any organization for digital design thinking and innovation which will help any organization to get the competitive advantage (Please see Table 2, figure 2, 3).

\begin{tabular}{|c|c|c|c|}
\hline Site & Keyword & $\frac{\text { Login } @ \text { PU Bangalore, }}{\text { Search by topic, }}$ & Results \\
\hline $\begin{array}{l}\text { https://www.sciencedirect.c } \\
\text { om }\end{array}$ & $\begin{array}{l}\text { Neurostrategy and Design } \\
\text { thinking }\end{array}$ & Topic & $\begin{array}{c}2(\text { Journal })+1 \\
\text { Conference abstract }\end{array}$ \\
\hline $\begin{array}{c}\text { http://ubc.summon.serialssol } \\
\text { utions.com }\end{array}$ & $\begin{array}{l}\text { Neurostrategy and Design } \\
\text { thinking }\end{array}$ & Topic & $\begin{array}{c}11(\mathrm{Jr}=7, \text { Book } \\
\text { review }=1, \\
\text { Newspaper article } \\
=2, \text { Dissertation/ } \\
\text { Thesis }=1)\end{array}$ \\
\hline https://scholar.google.com & $\begin{array}{l}\text { Neurostrategy and Design } \\
\text { thinking }\end{array}$ & Words & 93 \\
\hline https://www.scopus.com/ & $\begin{array}{l}\text { Neurostrategy and Design } \\
\text { thinking }\end{array}$ & Title/ Abstract/Keywords & 0 \\
\hline http://mjl.clarivate.com & $\begin{array}{l}\text { Neurostrategy and Design } \\
\text { thinking }\end{array}$ & Word/ Title/Keyword & 0 \\
\hline
\end{tabular}

Table:2, Source: Author's own research data

\section{Publication on Neurostrategy and related topics in ProQuest}

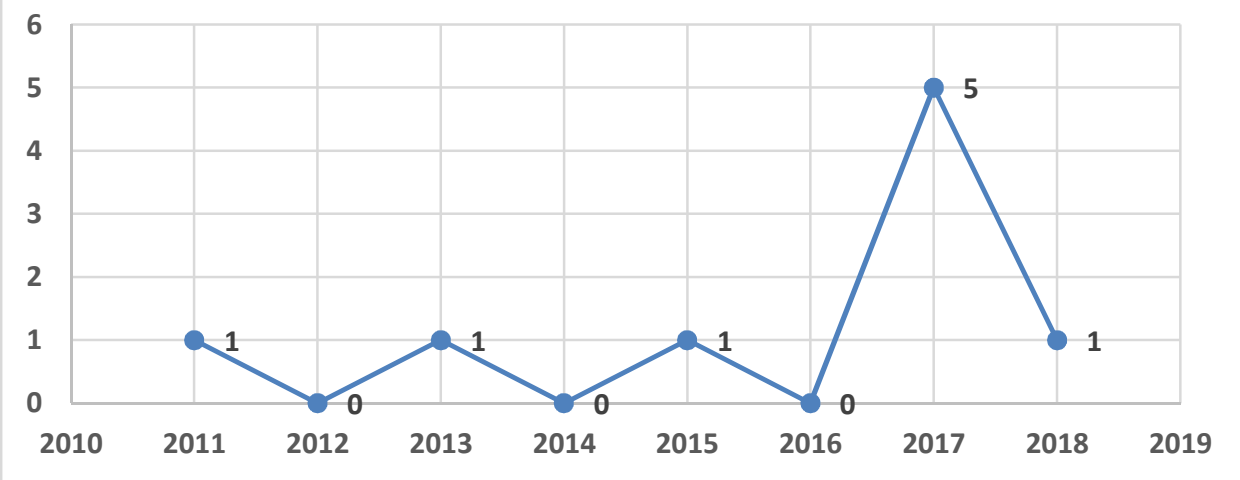

Figure:2, Source: Author's own research data

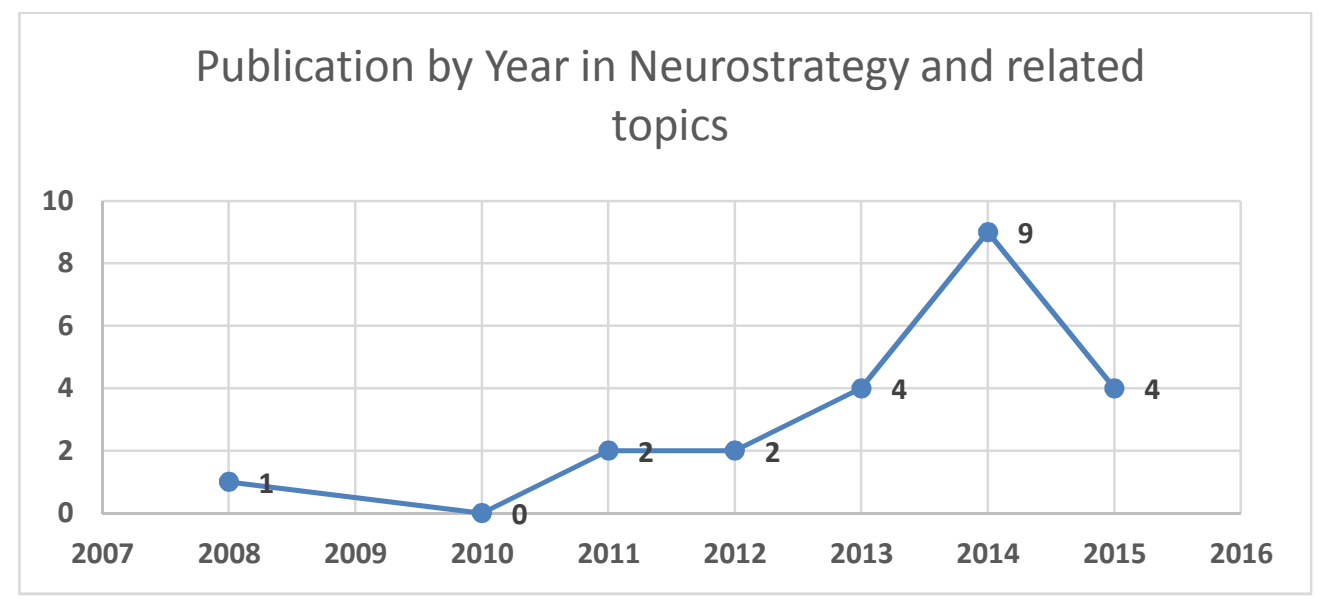

Figure: 3, Source: Author's own research data 


\section{Process of design thinking:}

Digital design thinking and regular innovation for an organization are two different things. The systematic thinking process is consist of ideate, define, design and develop stage but in the digital design thinking process empathize with the customer is more clear which can direct any organization to innovate.

Empathize is the first step in this phage. It will help the organization to recognize and pay attention to the customer's needs and want. To appraise this concept any organization can use the empathy map at this stage. The second step is define. In this stage, an organization has to amalgamate all the problem they are facing in the real ground and should come to the inference of defining the problem. After framing the problem, an organization can come with a different solution of the products. Ideate is the stage where brainstorm or ideate can help to come up with the result. Here a multidisciplinary team also can contribute immensely. At this stage finalize the best and reject the rest (Please see Figure 4).

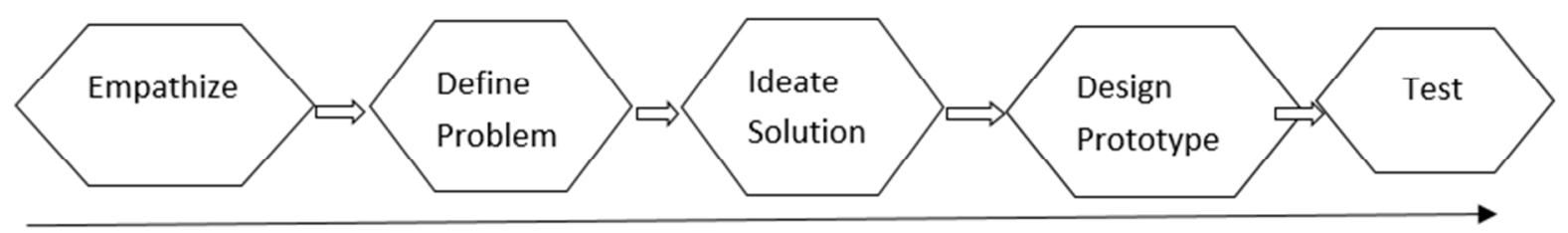

Figure 4: Process of Design thinking

Prototype brings a solution of the problem by a 3D diagram, clay model, sketching etc. This is a miniature form of the product. Here organization can use prototype or minimal viable product. Finally it is test stage, at this stage test the prototype with the customer and take a feedback regarding where this product is going to meet the expectation of the final user or not. If it is not selected by the customer than the organization has to follow the same path once again.

\section{Innovative Organization:}

Every organization wants to be innovative in some point of the life cycle of the organization, but due to some technological, political, economic and social factor organization may not be in a position to ensure new product development.

The organization which has built an innovative culture may get the benefit out of this. The organization which has an innovative culture may have certain pinpointed component to look into.

An Innovative organization should allow the employee think differently in their domain, there should not be a fear factor involved in this outcome. They can learn from the failure which could the first step for the success of the project or product or service.

Organization should have a clear-cut guideline about the innovation and it should be in the DNA of the organization.

This matrix should have a certain factor like Input, throughput, output, leadership, competency, climate and efficiency of the organization. To develop an innovative product or idea, leader's involvement in this journey is very much important. A leader should always motivate the team to do the good works. Here management should have a certain steps wise guideline for the innovation and have a logical thinking behind the decision.

\section{Challenges in design thinking:}

There is always a high risk involved in the digital designing thinking process. At a certain point of time designer may not know that the model he or she has made is not liked by the customer, then it has to remodel once again.

Organization spends money on the innovation and expectation is predictable operation efficiency and return on investment and how will be conveyed through a superior knowledge to the customers. There is always a calculative risk in this business. If it is clicked you can get a jackpot or otherwise you will be losing your bottom line. A leader needs to create an organizational culture that will allow people to innovate and help them to move forward.

Organization has to continuously add value to the innovation process so that they can attend newer height in the innovation ladder. Otherwise, a competitor will get the opportunity to copy the product or services easily. The biggest challenge for the organization is to enhance the creativity of the employee to make the product very much user-friendly with value addition and cost-effectiveness.

\section{Digital Transformation of design thinking}

Digital design thinking is very much crucial for any organization to succeed in the digital economy.

Digital design thinking is very much critical for the organizations to succeed in the digital economy. Any industry looks for an innovative mindset and methodology to create innovations that bring together of customer experience of usability, technology feasibility and business viability of an organization.

This is an empathetic approach to the targeted customer to discover the unmet needs of them. 
By focusing on collaborating experience of human capital, organization can use digital design thinking process to bring all department in a same platform, which will ultimately help to achieve the organization vision.

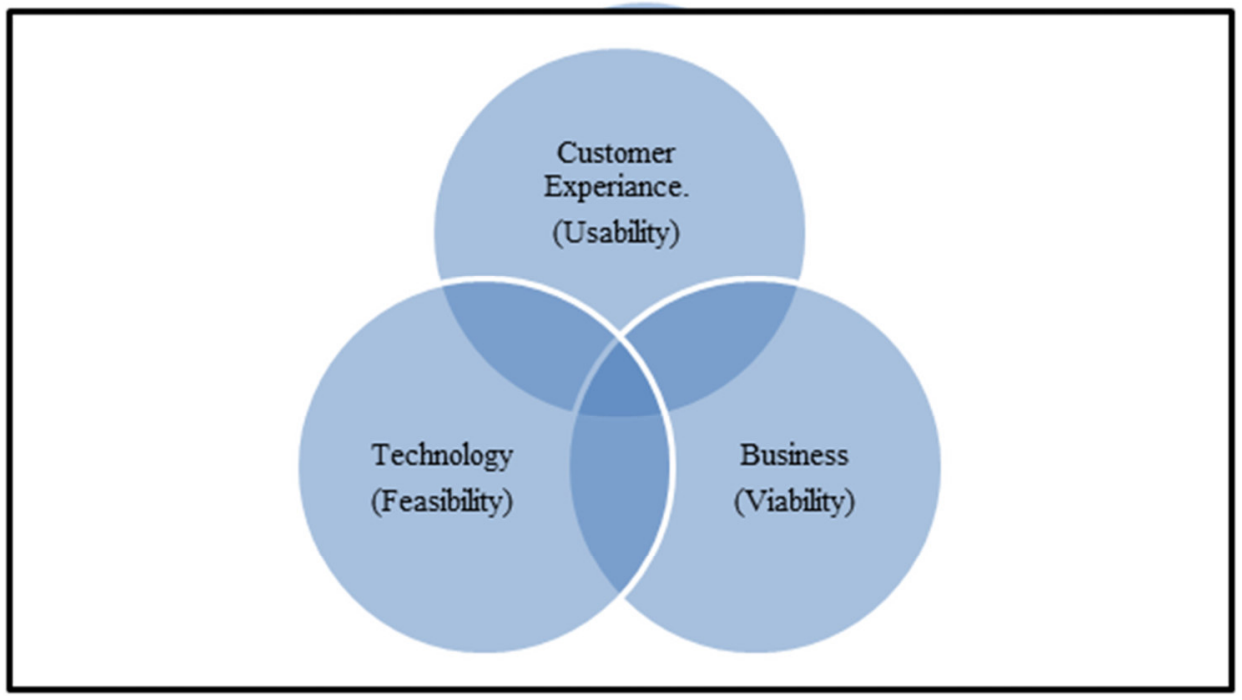

Figure 5: Digital Designing thinking and digital transformation relationship.

It can be stated that digital change is reinventing the business performs. Around the world, technological competences are incessantly cultivating and in order to keep up, organizations must be responsive and pioneering as they integrate these digital technologies into their day to day business performs (See figure 5). To stay competitive in any market, having a digital transformation strategy is a must.

The switch from business as usual to digital first is no easy feat - our digital world fluctuations rapidly and impulsively. Keeping up can present a contest and leave many unsure of how to grow. This is where design thinking comes in.

Design thinking is a stepwise, user-centric design process that does not present a details upfront but observes both present and forthcoming facts of a problem and discovers alternating outcomes.

Digital technology transform presents problems that are multifaceted and vague in nature. So, using design thinking to encirclement your organization's digital change helps clash these problems by using a fluid, flexible, practical method to interact with consumers and derived with results. After the improvement of the customercentric product, some of the recently talked technology like SMAC can help the organization to reach the customer for the product.

Digital Business facilities customers have been hugely successful in using design thinking across a range of business processes and technologies ranging from customer commitment, digital marketing, connected experiences and business analytics. These include an outline of new products using wearable internet of things, the progress of a banking product and new healthcare product or healthcare models for community care.

\section{The Neurostrategy and big data analysis:}

Author Carla Nagel raised a very exciting question about neurostrategy and big data. In an article "competing or completing for improved consumer understanding" in Neurostrategy Theory \& Practice, (Nagel 2015, p.24), if both of them nurture properly, it will be the "the next big thing" in the strategy area.

Both the area of neurostrategy and big data are able to deliver valuable information about targeted customer and their behavior. It will helps any organization to do segmentation, targeting and positioning of the product successfully. As neurostrategy and big data applications has a shared area of working, collection, and examination of huge data, but significantly, the concluding objective is to use this information for right result and that is the tailback in both of these developing fields.

It is easy to collect and store more terabyte data from numerous sources or from progressive neurostrategy approaches but it is much tough to convert this database to support the business decision- making process.

The data which is available within the organization are heterogeneous in source and difficult to manage because of its amorphous and unrelated nature. Conventional business analysis like co-relation and regression has a limitation to process that data base. Here big data analysis and artificial neural network can help the organization to disclose the knowledge from hidden pattern. This is the collaborating point of big data, neurostrategy and artificial neural intelligence.

The cutting edge technology has a capability to recognize unseen assemblies from the data base. Organization can get more understanding about the customers by applying the data mining technology and artificial neural intelligence to neurostrategy. The result of the same can be called something new like "DNA of 
mind mining" (See figure 6).

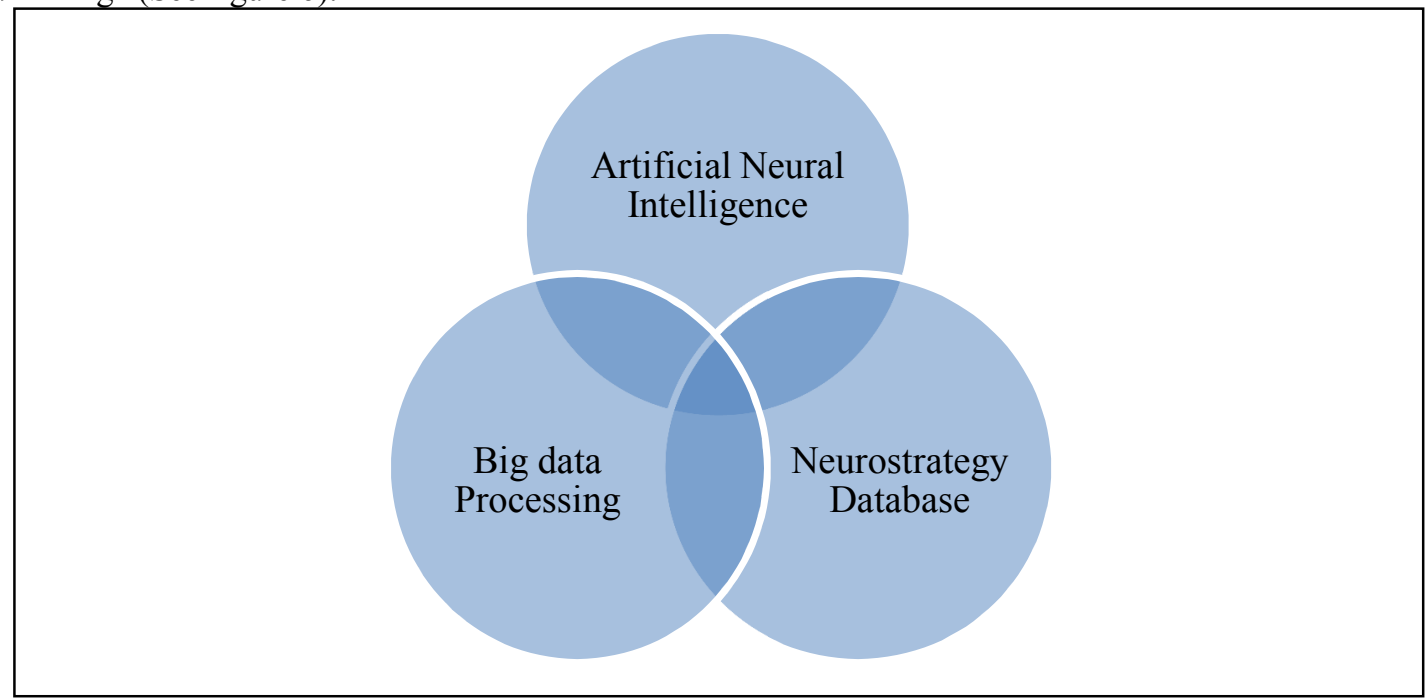

Figure:6, Pitch point between Neurostrategy, Big data processing, and Artificial Neural Intelligence.

An organization is collecting more and more data every day from various reliable sources, but most of the organization are facing problem to use that data for business decision outcome. All the collected data need to be convert into expressive executable knowledge for the organization.

Therefore nowadays for any organization, challenge is not to collect and get the database, but it is a big challenge to them to analyze the (right) data for knowledge discoveries to support real-time and perspective upcoming activities.

In this respect, data mining technique of predictive analysis is gaining acceptance day by day. This technique can reveal complex, nonlinear and dynamic relationships - such as those found in living systems - and can be helpful to solve the artificial neural intelligence practical problem.

In neurostrategy, customer understanding allows the marketer to connect with customers innovatively beyond tangible touch points, beyond brick mortar stores, through smartphones or through tablet apps. Numerous brands are advertised and reach the customer and a customer gets bewildered by the advertisement, ultimately the emotional and logical mind makes the final purchase decision. The general understanding or overview of the consumer decision-making process is not possible to get via conservative marketing research methods (Ariely \& Berns, 2010). This believed is mostly supported by the logic that customer cannot (or do not want to) fully explain their liking and disliking process when explicitly asked (Calvert \& Brammer, 2012). In this situation, the effect and magnitude of effectiveness of various engagement activities may be calculated by analyzing customers' brain activity resulting from dissimilar factors of advertisement, product, and service attributes (Astolfi , 2009; Ohme, Reykowska, Wiener, \& Choromanska, 2009).

\section{Sustainable Business Growth:}

According to C K Prahalad in his article on "Why Sustainable is now the key driver of innovation" The organization which has started the journey towards the sustainable concept, has to go through five distinct stage of change which is defined in given diagram. So it can be said that designing thinking(Stage:3) is a part of a sustainable journey and if it gives fuel to any organization for this development it will consider as a smart designing(See Figure 7).

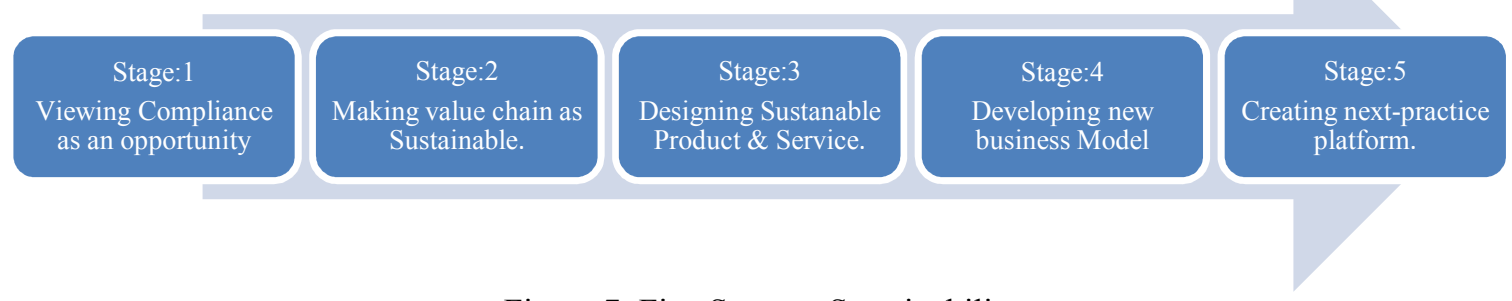

Figure 7: Five Steps to Sustainability

The Balanced Scorecard (BSC) is a management appraisal system for any organization. It's a way of observing and examining any organization that emphases on strategic goals. It also helps to select the right things to measure so that the organization can reach the goals and vision of any organization. If any organization 
want to be very perspective in Balanced Score Card analysis, designing thinking can surely take care of the customer value proposition portion which in turn can take care of the financial perspective of any organization.

\section{Future Model}

The success of the product, process or service outcome of digital design thinking will help the organization to achieve the vision. A SMART(See figure 8) model of design thinking has five windows.

Sustainable: This window talk about a strategic viewpoint of digital design thinking which will give an organization long-term sustainable benefit as the output of the system has its novelty in character. As the need and want of the customer are identified here, chances of new product letdown will be less and it will create differentiate and sustainable advantage in long perspective.

Measurable: This window talk about the financial scenarios of the design thinking. It will help to calculate the financial prospects of the product or service. It will also help in to measure input, throughput, and output of the design thinking.

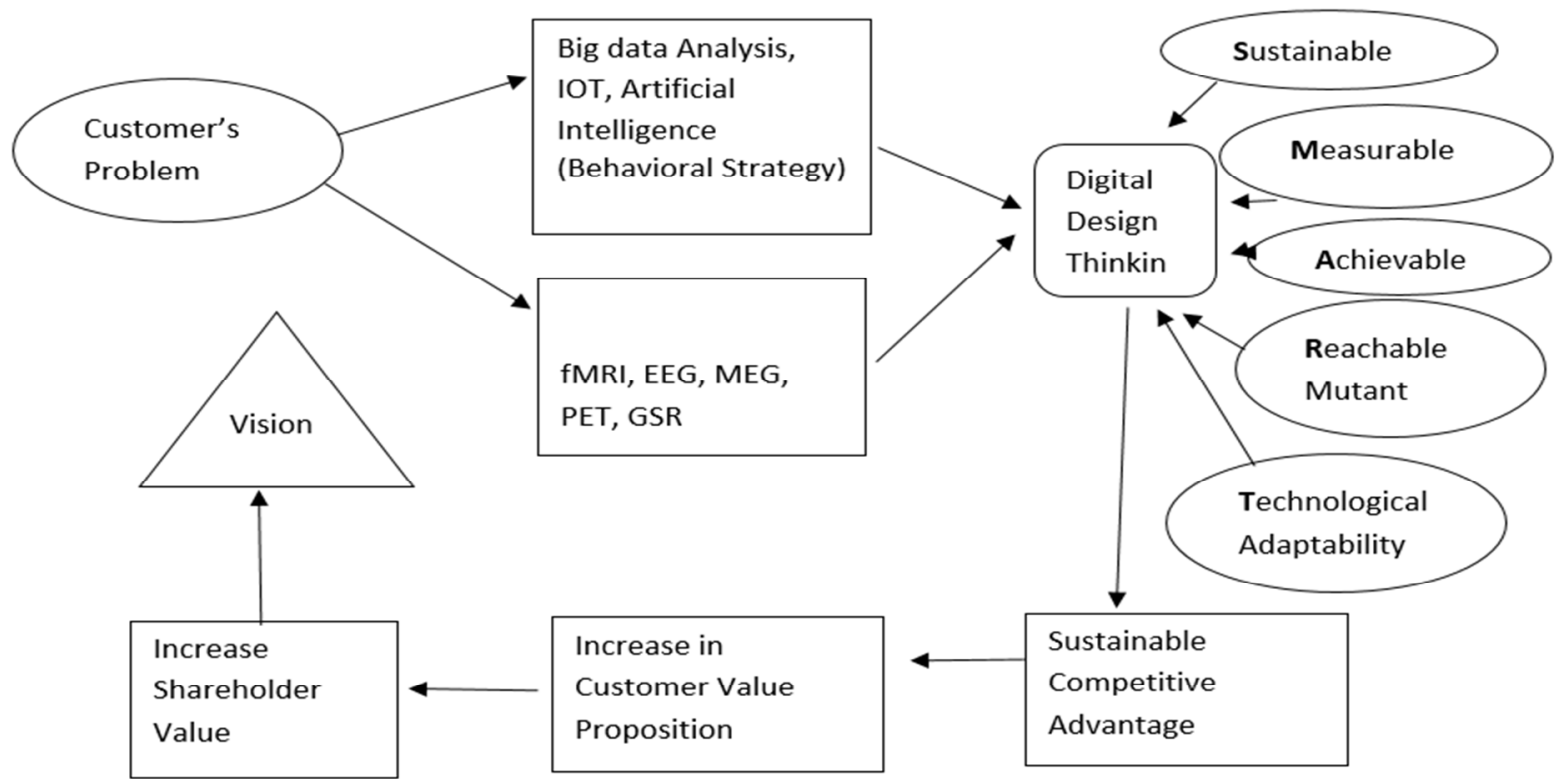

Figure:8, Digital Design Thinking (SMART Model) Framework

Achievable: Many concepts may come through the designing thinking process, but the biggest question would be whether this product or service is possible in nature or not. The design thinking procedure should deliver an attainable output to the organization.

Reachable Mutant: This window talks about value addition prospective of the output (Product or Service). When the new product of the organization will launch in the marketplace, a competitor will try to copy it. At this point, the product has to work like a mutant object by some value addition to the product so that external competitor is unable to destroy the product but at the same time the mother product can destroy the competitor by directing the customer towards its benefits.

Technological Adaptability: This window will talk about the continuous improvement of the output. So that it will work like a reachable mutant, can create a sustainable advantage, it can measure the output and the product or service design can be easily achieved. This factor also can create fencing around the product or services.

\section{Analysis and Discussion:}

Powell (2011) stated that "In strategic management, some academician may think that whether process within the individual brain can enlighten research that takes the organization and industry as its primary units of examination". As on today, though some researchers are going to do research on neurostrategy, but still there is some hesitation about its importance and there are lots of difficulties for article publication in this subject.

For a healthier understanding of what is digital designing thinking is all about, neurostrategy method also can help in this regards. There might be a conflict from the result of behavioral and psychological point of view of a customer (Leureiro- Martinez et al, 2015). In this situation, neuroscience by using the medical tools are able to find the correct decision among them.

Dealing with the digital design thinking with neurostrategic potential has many constraint. There will be some reverse influence problem in association of activation of brain and mental state (Nicolaou \& Shane, 2014). Another issue will be replacing of previous study outcome by neuroscience result without considering the variable that were considered in the previous study. 
Other restraint of digital design thinking with neuroscience might be lying in restlessness around the tools of neuroscience like fMRI, EEG. It is always a challenge for manager how to read the brain scan result and how to co relate those result in to management theories and practice.

Ward et al.(2015) noted that neusoscience consequences has a great effect on public and press because of their robust scientific criteria.

Some others (Bennett \& Hacker, 2003; Laureiro- Martinez et al., 2015) speak the ethical issues about the neuroscience. In some cases idiosyncrasies effect of brain can be seen if proper training of the subject not given to the researcher.

\section{Future research guidance}

Though the digital design thinking process and outcome is not the new concept to the academics fraternity of this world, it always gives a challenge to the designer, to come out with a winning combination of outcome, so that the final user will accept that wholeheartedly. If any organization succeeds than it will be jackpot otherwise organization will lose the game. By the analysis of the above discussion, it is very much clear that digital design thinking helps the organization in new product development, which could be winning step for the organization. It will also create some fencing to protect the product from the competitors. The above discussion will give future research guidance, how design thinking will be a competitive advantage to the organization from a neurostrategic window.

\section{Managerial Application}

Work by Tabibnia(2008) and Boyatzis et al (2012) endorse that it will help to set the positive vision of an organization. Butler et al (2016) stated that some of the organization are active to this concept for a professional support. Powell(2011) said Neurostrategy consultant are evaluating consumer's cognitive and emotional response for new product development. Brain scans are also used in law to reveal the capacities of defendants, and to predict punishment in jury decisions (Powell, 2011). Balthazard et al(2012) proposed that there is possibility of neurologically assessment behavior of leadership style and competency.

Neurostrategy will supports in a circumstances and backgrounds where the decision maker is unaware or unable to articulate why any specific behavior exhibits by a customer in a given situation. Neurostrategy techniques can provide information about implicit procedures that are typically problematic to access using other methodologies. Neurostrategy and other neuroscientific methods can be leveraged to improve understand specific differences and thereby clarify the sources of heterogeneity in consumer behavior (Venkatraman et al. 2012).

\section{Conclusion and recommendation}

The objective of this article is to know the impact of digital design thinking from a neuostrategic point of view by review of international journal. The review work conclude that, despite incomplete amounts of scientific research and studies on neurostrategy, research done by Powell in 2011, has given the guideline to other researcher to work in this promising field of management. But lack of proper infrastructure and research guideline has increased the difficulties to apply the neuroscience tools in digital design thinking process.

Powell(2011) also talked about that neurostrategy can heavily contribute to customer choice procedure if digital design thinker are very much precise about their neurostrategic research problem.

Based on Kuhnian viewpoint, neurostrategy cannot change the complete focus of studies in Digital design thinking but could be a substitute way to deal with some happenings in a digital design thinking by using new tools and that can get more answers to existing results found by normal science in digital design thinking.

The present research adds to current knowledge concerning the theoretical foundation and antecedents of digital design thinking as a part of new product design. Every organization can think about the design thinking as a part of the successful journey but the challenges are the more inhuman domain. The organization has to create an innovative design thinking culture and mindset among the employee. The basic of the concept will come from empathizing of customer need \& want and how to full fill that needs and want with suitable product or services with minimum resources utilization. Digital design thinking will also help an organization to come up with a very creative product which can be patented by the law. Then this product will give a competitive advantage to the organization for a long time, with the help of this innovative product organization can penetrate the market or can get a skimming advantage. Though this concept is more commercial oriented organization also has to think from research window advantage perspective. If the organization is able to establish the concept of SMART design thinking in a strategic perspective, then the organization will get an advantage in a competitive environment of the industry.

\section{References}

- $\quad$ Ackoff, R. A Theory of a System for Educators and Managers. Vol. 21. 
- $\quad$ Akin, Ö., \& Akin, C. (1996). Frames of reference in architectural design: Analyzing the hyper-acclamation (aha!). Design Studies, 17, 341-361.

- Ashkanasy, N.M., Becker, W.J. \& Waldman, D.A.(2014). Neuroscience and organizational behavior: Avoiding both neuro-euphoria and neuro-phobia. Journal of Organizational Behavior, 35(7), 909-919.

- Bhandari, A. (2013). Strategic Management - A Conceptual Framework, McGraw Hill Education, New Delhi, India.

- $\quad$ Buchanan, R.(1992). Wicked Problems in Design Thinking. Design Issues, 8 (2).

- Braha, D., \& Maimon, O. (1997). The design process: Properties, paradigms, and structure. IEEE Transactions on Systems, Man, and Cybernetics-Part A: Systems and Humans, 27, 146-166.

- $\quad$ Braha, D., \& Reich, Y. (2003). Topological structures for modeling engineering design processes. Research in Engineering Design, 14, 185-199.

- Chandler, A.D. (1962). Strategy and Structure: Chapters in the history of the industrial enterprise. Cambridge, Massachusetts: MIT Press.

- $\quad$ Cooper, R. \& Press, M (1995), The Design Agenda. London: John Wiley \& Sons.

- Cristofaro, M.(2017), " Herbert Simon's bounded rationality: its historical evolution in management and cross-fertilizing contribution". Journal of Management History, 23(2), 170-190.

- Dunne, D., \& Martin. R. (2006). Design thinking and how it will change management education: An interview and discussion. Academy of Management Learning \& Education, 5, 512-523.

- $\quad$ Dorner, D. (1999). Approaching design thinking research. Design Studies, 20, 407-415

- $\quad$ Evans, D. L., McNeill, B. W., \& Beakley, G. C. (1990). Design in engineering education: Past views of future directions. Journal of Engineering Education, 79, 517-522.

- $\quad$ Gharajedaghi, J.(2006) Systems Thinking: Managing Chaos and Complexit Butterworth-Heineman.

- $\quad$ Gippel, J.K.(2013). A revolution in finance? Australian Journal of Management, 38(1). 125-146.

- Hodgkinson, G.P. \& Healey, M.P. (2011). Psychological foundations of dynamic capabilities: Reflexion and reflection in strategic management. Strategic Management Journal, 32(13), 1500-1516.

- Jon Kolko(2015) Design thinking comes of age, September 2015, Harvard Business Review.

- Laureiro-Martinez, D.,Brusoni, S.,Canessa, N.\& Zollo, M. (2015).Understanding the explorationexploitation dilemma: An FMRI study of attention control and decision-making performance. Strategic Management Journal, 36(3), 319-338.

- $\quad$ Mintzberg, H., \& Waters, J. (1985). Of Strategies Deliberate and Emergent. Strategic Management Journal.

- Naidumolu, Prahalad, Rangaswami (2009) Why sustainability is now the key driver of innovation, R0909E, Harvard Business School.

- Owen, C. (2007). Design thinking: Notes on its nature and use. Design Research Quarterly, 2, 16-27

- $\quad$ Porter, M., (1985) Competitive Advantage: Creating and Sustaining Superior Performance. NY: Free Press.

- $\quad$ Powell, T.C.(2011). Neurostrategy. Strategic Management Journal, 32(13), 1484-1499.

- $\quad$ Powell, T.C. (2014). Strategic Management and the person. Strategic Organization, 12(3),200-207.

- Powell, T.C.(2017). Strategy and diligence: Putting behavioral strategy into practice. California Management Review, 59(3), 160-190.

- Prahalad, C.K. \& Hamel, G.(1990). The core competence of the corporation. Strategische Unternehmungsplanung-Strategische Unternehmungsfuhrung,68, 275-292.

- $\quad$ Rifkin, J., (2001) The Age of Access: The New Culture of Hypercapitalism. Tarcher.

- $\quad$ Rylander, A., (2009) Design Thinking as Knowledge Work. DMI Journal, 4 (1).

- Senge, P., 2005. Presence: Exploring Profound Change in People, Organizations and Society. Boston: Nicholas Brealey.

- $\quad$ Sennett, R.,(2007) The Culture of the New Capitalism. USA: Yale University Press.

- Shute, V. J., \& Becker, B. J. (2010). Innovative assessment for the 21st century. New York, NY: SpringerVerlag.

- $\quad$ Simon, H. A. (1996). The sciences of the artificial (3rd ed.). Cambridge, MA: MIT Press.

- $\quad$ Teece, D.J., Pisano, G. \& Shuen, A. (1997). Dynamic capabilities and strategic management. Strategic Management Journal, 18(7), 509-533.

- Thaler, R.H. (2000). From homoeconomicus to homosapiens. Journal of Economics Perspectives.

- Ward, M.K., Volk, S. \& Becker, W.(2015). An overview of organizational neuroscience.

- Wernerfelt, B.(1984). A resource-based view of the firm. Strategic Management Journal, 5(2), 171-180.

- Wolf, B. (2008) Attitude is Essential: Brand, Reputation and Design Management in Small to Medium Enterprises. Hogeschool Inholland. 